\title{
I.S.P. Nation, Learning Vocabulary in Another Language. Cambridge: CUP, 2001, 417p.
}

Reviewed by Raquel Fernández Carril

University of Santiago

In the last few decades, vocabulary has undergone a re-emergence of interest in the field of second language acquisition, as a reaction against years of abandonment and obscurity. Researchers such as Ronald Carter and Michael McCarthy have demonstrated that vocabulary knowledge is a basic premise to develop almost any language skill. Moreover, recent studies gathered the conclusion that vocabulary acquisition do not occur by itself, but needs to be dealt with in language instruction. Unfortunately, it is still not clear how lexical enhancement can be reinforced.

A research group from Victoria University in New Zealand led by Paul Nation has devoted many years of study to illustrate the best way of facing 's task. Based on results obtained from years of empirical research on word frequency lists, Nation's main contribution lies on the idea that, once analysed the necessities of a L2 learner, there is a core vocabulary (around 2000 word families) that can be identified and that should be directly taught. After this core vocabulary has been assimilated, then it is preferable spending time on developing learning strategies that help learners increase their vocabulary size, until $95 \%$ of the common words are known in an average text. This systematic approach to vocabulary acquisition is unusual in the area of second language acquisition.

This book is structured into eleven chapters following a well established pattern that comprises all the aspects of both learning and teaching vocabulary in another language. The first two chapters introduce the reader to the main goals of vocabulary learning and the main features involved in knowing a word. Both chapters act as a general framework for the following eight sections devoted to the different elements entailed in the process of teaching vocabulary, such as L2 vocabulary and the four skills: listening, speaking, reading and writing, vocabulary learning strategies or chunking and collocation. The last chapter presents a good example of what the author has developed in the previous ones for it contains a well-balanced course design for vocabulary enhancement. Furthermore, in the introduction, Nation states that the book was designed according to the four major strands, that is to say, meaning-focused input (learning through listening and reading activities), language-focused learning (direct teaching/learning of vocabulary), meaning-focused output (learning through speaking and writing activities) and fluency development. For him, the four strands need to be borne in mind when teaching vocabulary and this book aims to be a reflection of how the lexicon arranges into them.

In chapter 1, Nation explores the number of words in English, the number of words known by native speakers and, consequently, the number of words that foreign speakers need to use the language fluently. After a series of congruent analyses using frequency digital corpora (just as the ones employed by the Cobuild dictionary) it is stated that the learner going on to academic study needs to know 2000 or so high-frequency words plus 
around 15000 and 20000 technical and low-frequency elements. To cope with such a great amount of foreign vocabulary, it is argued that time should be spent on directly teaching these high-frequency words. However, it seems wiser to train learners in the use of vocabulary learning strategies when dealing with the low-frequency ones, instead of teaching each of them.

"Words are not isolated units of language...there are many things to know about any particular word" (p. 23): with this clear statement, Nation emphasises in chapter 2, the cumulative nature of word knowledge and the main aspects involved in it. He frames the difference between receptive and productive knowledge, meaning by receptive the perception of a word form while listening or reading and retrieving its meaning; whereas retrieving and producing the oral or written expression of an intended meaning would be productive knowledge. All of these aspects are extremely important and deserve the teachers' attention.

Then and according to his systematic way of working, Nation brings forward a complete set of activities designed for vocabulary learning to take place, taking into account learning goals and psychological conditions implied. Nation firmly believes that learners can greatly benefit from both the oral skills (listening/speaking) and reading and writing. Repetition is strongly encouraged throughout the activities. It is quite remarkable that the author is constantly making use of new technologies and so computer-assisted vocabulary learning is also presented as a profitable way of putting this theory into practice. ${ }^{1}$

Throughout the first five chapters, Nation's point of view is extremely clear: he will not carry on with the secular dichotomy between direct and indirect teaching. He considers both and encourages teachers to make use of them without prejudices. Quite on the contrary, teachers can benefit from them depending on the concrete learning stage, as it is reflected in the series of brilliantly designed activities mentioned before.

Another point worth mentioning is the author's concern about tackling all the aspects of vocabulary learning. He does not present vocabulary as isolated items but as a unity conveying a message in the shape of a text, which has to be borne in mind when designing a vocabulary-teaching plan, based on Halliday's field, tenor and mode. Nation points out the relevance of academic vocabulary for learners with scientific and academic purposes and so he suggests the design of academic word lists and tests so as to learn them. In the case of technical vocabulary, that is full of low-frequency words, the author encourages the use of vocabulary learning strategies.

As stated before, his direct and clear style leads to concrete and unambiguous directions on how to cope with that apparently unapproachable task of facing foreign vocabulary. He insists on the advantages of spending time on teaching high-frequency words, for they are a relatively small amount and may be used in almost every occasion. However, there are other words, the so-called low-frequency ones that are better learned by means of vocabulary learning strategies. Thus, in the three following chapters, "Vocabulary learning strategies and guessing form context", "Word study strategies" and "Chunking and collocation", those means of dealing with low-frequency words are brought forward. 
Then, an extensive taxonomy of vocabulary learning strategies based on Schmitt (1997) and Oxford (1990) is divided into three groups: (1) strategies employed in choosing what vocabulary is to be learned; (2) strategies used to find information about the word itself; and (3) strategies aimed at establishing words already known. Teachers are urged and guided to encourage and train learners in the use of the aforementioned strategies, by showing them several studies on learners' use of strategies and providing them with procedures to integrate these strategies in their everyday course. Nation argues that in spite of having the drawbacks of incidental learning, i.e., one can never be certain if learners are correctly learning, guessing from context is the most powerful tool for increasing vocabulary and as such, it deserves time and effort for teaching and learning. He takes into account all the factors entailed in this complex strategy and he brilliantly suggests ways of approaching it, both for high and low frequency terms.

In opposition to those scholars who criticise the exploitation of decontextualised learning (Judd 1978; Anderson and Nagy, 1992), the author encourages the use of dictionaries and word cards, for they allow learners to focus on those aspects of word knowledge not easily covered by context learning and help learners control their own learning process. In the final chapter of this set, Nation points out frequent collocations as one of the main sources of native fluency of speech and as such, he insists on the convenience of spending time on learning them. Furthermore, some of them are highly frequent so they also deserve attention. The author goes on and brings forward ten criteria for classifying collocations and encourages teachers to train learners in chunking as the major means of analyses, providing a series of activities to practise that strategy. Nevertheless, one wonders whether due to space limitations Nation did not pay the expected attention to the best way of training learners in the use of these vocabulary learning strategies.

The last part of the book deals with one of the most important steps of teaching vocabulary: that of evaluation. Nation argues that there is not single "best vocabulary test" but a wide range of vocabulary test, formats according to: (a) the purpose of the test; (b) the kind of knowledge it will measure; and (c) the various aspects comprised in knowing a word and the conditions under which it will be administered (including multiple-choice, translation, context embedding and so on).

Finally, one of the most striking features of this book lies in the fact that it is not only a theoretical view about teaching and learning vocabulary but it also contains a clear exemplification of all the issues tackled throughout the whole book. It shows how to design a language teaching course focusing on vocabulary taking into account the elements mentioned in the previous chapters. Nation's ultimate goal is clearly that of any teacher: turning students into autonomous learners, taking control over their own learning process.

Despite the fact that much has to be done to improve both teaching and learning vocabulary, Learning vocabulary in another language provides a great contribution to this field of applied linguistics from which teachers and learners of second and foreign languages can obviously benefit. The clarity and directness of expression which characterise this volume are predictable considering that the author is an experienced researcher aiming 
at providing pedagogical advice. Combining a solid theoretical basis and a great amount of well-chosen and recent bibliographical references, as well as the numerous examples of vocabulary learning strategies, activities and tests make this book a starting point for any vocabulary teacher or course designer, whose goal is to train their students to be more successful vocabulary learners.

Against those who consider vocabulary as something quite annoying to face, Nation presents vocabulary as a subject that can be systematically approached, analysed and taught, which benefits from almost every learning style, and it is here where his major strength lies.

\section{Note}

1. On his web site, Nation has developed downloadable computer programmes that examine vocabulary in texts (www. vuw.ac.nez/lals/staff/paul_nation/index/html).

\section{Works cited}

Carter, R. and M. MacCarthy (1988): Vocabulary and Language Teaching. London: Longman. Nation, I. S. P. (2001): Learning Vocabulary in Another Language. Cambridge: Cambridge University Press.

Oxford, R. (1990): Language Learning Strategies: What Every Teacher Should Know. Rowley, Mass.: Newbury House.

Schmitt, N. and M. McCarthy (eds.)(1997): Vocabulary: Description, Acquisition and Pedagogy. Cambridge: Cambridge University Press.

\section{Brooker, Jewel S. (ed.) T.S. Eliot and Our Turning World. Macmillan Press: Basingstoke and London, 2001. 238 pp.}

\section{Revewed by María Teresa González Mínguez}

One of the best achivements of T.S. Eliot in the twentieth century, that, no doubt, still persists in the twenty first, was to adapt intellectual poetry to a much wider international public. His works, characterized by irony, rooted with popular culture and scholarship, have been reabsorbed today by the world of music, fiction, cinema and theatre.

Jewel Spears Brooker, former president of the T. S. Eliot Society, agglutinates in this superb volume the different lectures of "T.S. Eliot and Our Turning World," a conference sponsored by the Institute of the United States at the University of London in 1996. The event clarified some aspects of the poet and playwright's complex personality -family relationships, his marriage, religious beliefs and political tendencies- considered until now peripheric to his literary production, using for this purpose the last publications about his philosophical works and literary criticism.

The first two essays deal with the sense of loss and spiritual hunger of the British author. Following those who met Eliot and talk about his exquiste courtesy towards children, 